\title{
Análise da disposição final dos resíduos sólidos urbanos no Distrito de Pilar-Ba
}

Analysis of the final disposal of municipal solid waste in the Pillar-Ba District

El análisis de la disposición final de los residuos sólidos urbanos en el Pilar-Ba Distrito

Andressa Leal

\section{Resumo}

Em função do crescente conhecimento nas implicações sobre o meio ambiente, do aumento populacional e consumo exacerbado, o alto volume de resíduos gerados a serem dispostos de forma inadequada, tem favorecido como grandes desafios tanto para os gestores públicos quanto para a sociedade $\mathrm{O}$ objetivo do trabalho foi avaliar o local de destinação final dos resíduos sólidos urbanos gerados no Distrito Pilar em Jaguarari-BA. O trabalho foi desenvolvido no período de janeiro de 2016. A primeira etapa, foi realizada no local de destinação final dos resíduos, através de visitas e observações in loco do lixão à céu aberto, às quais permitiram descrever os principais impactos ambientais presentes no ambiente de destinação final dos resíduos, e através de entrevistas para os moradores que moram no entorno do lixão, e funcionários da prefeitura. De acordo com os resultados, observou-se que os principais impactos diagnosticados foram: Resíduos depositados de maneira irregular, contaminação do solo, e águas subterrâneas, riscos aos catadores e impacto na saúde pública.

Palavras-chave: Meio ambiente, Lixão, Impactos ambientais.

\begin{abstract}
Due to the growing knowledge of the implications on the environment, population growth and exacerbated consumption, the high volume of waste generated are disposed of improperly, has favored as major challenges for both public officials and for society The objective it was to evaluate the site of final disposal of municipal solid waste generated in the District Pilar Jaguarari-BA. The study was conducted from January 2016. The first step was carried out at the site of final disposal of waste, through visits and on-site observations of the landfill to open, which allowed to describe the main environmental impacts in the environment of disposal of waste, and through interviews to residents living approximately the dump, and city officials. According to the results, it was observed that the main impacts were diagnosed:.
\end{abstract}


Waste deposited in an irregular manner, contamination of soil and groundwater risks to scavengers and impact on hublic health

Keywords: Environment, Dump, Environmental impacts.

\section{Resumen}

Debido al creciente conocimiento de las consecuencias sobre el medio ambiente, el crecimiento demográfico y el consumo exacerbado, el alto volumen de los residuos generados se desechan de manera inadecuada, ha favorecido como los principales desafíos tanto para los funcionarios públicos y para la sociedad El objetivo que fue el de evaluar el sitio de disposición final de los residuos sólidos urbanos generados en el distrito de Pilar JaguarariBA. El estudio se llevó a cabo a partir de enero de 2016. La primera etapa se llevó a cabo en el sitio de disposición final de los residuos, a través de visitas y observaciones en el lugar del vertedero para abrir, lo que permitió describir los principales impactos ambientales en el entorno de eliminación de los residuos, y por medio de entrevistas a los residentes que viven en las proximidades del vertedero, y funcionarios de la ciudad. De acuerdo con los resultados, se observó que los principales impactos fueron diagnosticados:residuos depositados de manera irregular, la contaminación de suelos y aguas subterráneas riesgos a los carroñeros y
el
impacto
en
la
salud
pública

Palabras clave: Medio ambiente, descarga, los impactos ambientales.

\section{Introdução}

O crescimento da população urbana, e o consumo desenfreado, têm de maneira considerável, contribuído para o aumento da geração de resíduos sólidos urbanos. Entretanto, o manejo inadequado desses resíduos de qualquer origem gera desperdícios, contribui para degradação ambiental e ameaça à saúde pública, comprometendo a qualidade de vida das populações especialmente nos centros urbanos.

O lixo urbano, ou seja, os resíduos sólidos urbanos (RSU) quando acumulado e iniciado o processo de degradação do mesmo produz um líquido denominado de chorume. Este possui coloração escura com cheiro desagradável e atinge as águas subterrâneas (aquífero, lençol freático) (ARAÚJO et al., 2013).Os impactos ambientais ocasionados pelo chorume surge pela decomposição dos resíduos, se infiltrando no solo pode ocasionar a contaminação de águas superficiais e subterrâneas e o assoreamento dos riachos, por apresentar uma alta concentração de matéria orgânica ,outros poluentes, os quais podem agregar outros riscos ao homem e ao meio ambiente (substâncias inorgânicas, metais pesados). 
A Associação Brasileira de Empresas de Limpeza Pública e Resíduos Especiais (ABRELPE, 2013), revela que 3.344 municípios ainda fazem usos de locais impróprios para destinação final de resíduos. Desse total, 1.569 municípios utilizam lixões, mesmo esse seja uma forma inadequada de disposição final.

O gerenciamento inadequado dos resíduos afeta todas as outras áreas do saneamento (esgotamento sanitário, abastecimento de água e drenagem de águas pluviais urbanas) e causando variáveis problemáticas ao meio ambiente, à saúde e às condições sociais do homem, além de constituir crimes ambientais (SILVA et al., 2011).

A disposição inadequada dos RSU promove consequências graves, como exemplo o assoreamento de rios e canais devido o lançamento de detritos nesses locais, a contaminação de lençóis de água comprometendo o seu uso domiciliar, contaminação do solo por intermédio da infiltração dos líquidos percolados gerados a partir do processo de decomposição e degradação da fração orgânica, a proliferação de insetos, roedores, transmissores de doenças, e o problema da presença dos catadores nos locais onde os resíduos sólidos são depositados a céu aberto (JUNKES, 2002;ALCANTARA, 2010).

A obtenção de um diagnóstico sobre a situação das características naturais na área do Lixão, no município de Pilar-BA, servirá como instrumento inicial para implantação de ações concretas de preservação ambiental. Em que consiste num processo que envolve as ações relativas à tomada de decisões políticas e estratégicas ambientais relacionadas aos resíduos sólidos.

Diante disso, o objetivo do trabalho foi desenvolver uma análise da disposição final dos resíduos sólidos urbanos depositados em lixão a céu aberto, no Distrito de Pilar - BA.

\section{Materiais e Métodos}

Área de Estudo

O trabalho foi realizado no Distrito de Pilar situado no estado da Bahia, distando aproximadamente $550 \mathrm{~km}$ da capital, Salvador, com 30.343 mil habitantes, em uma área de $2456.548 \mathrm{~km}^{2}$ (IBGE, 2010).

A pesquisa in loco foi realizada no lixão localizado no Distrito de Pilar no qual distancia-se 2,7 km quilômetros do perímetro urbano (Figura 1), com área total de 9,28 hectares. Sob as coordenadas geográficas de longitude 40,1844 "W, e latitude -10,2436 "S. 
Trata-se de uma pesquisa exploratória de caráter descritivo do processo de coleta e disposição final de resíduos sólidos urbanos. A pesquisa exploratória tem por objetivo aproximar-se do tema, criando maior familiaridade em relação ao fato ou fenômeno, prospectando materiais que possam informar a real importância do problema, o que já existe a respeito ou até novas fontes de informação, o que normalmente é feito através de levantamento bibliográfico e documental, entrevistas, observações in loco.

A primeira etapa foi realizada em janeiro de 2016 e consistiu na análise in loco das condições ambientais do lixão. Foi feito a observação do tipo de lixo descartado, os possíveis impactos sobre o solo, ar, fauna e flora. A identificação dos tipos, causas e consequências dos impactos ambientais na área de estudo foi realizada a partir dos impactos identificados, no qual foram selecionados os mais significativos para análise e interpretação dos dados.

Foi realizado um questionário (Anexo 1) com a população para avaliar os problemas que os mesmos vêm sofrendo devido às atividades antrópicas que afeta não apenas área de disposição final como também a qualidade de vida das pessoas. Aplicado também outro questionário (Anexo 2) com alguns funcionários da prefeitura do Distrito do Pilar, para obter informações sobre o lixão em si e quais procedimentos a prefeitura vem tomando para acabar com tais problemas.

Figura 1. Localização do lixão do Distrito de Pilar, em Jaguarari, BA (FONTE: Google Earth, 2015).

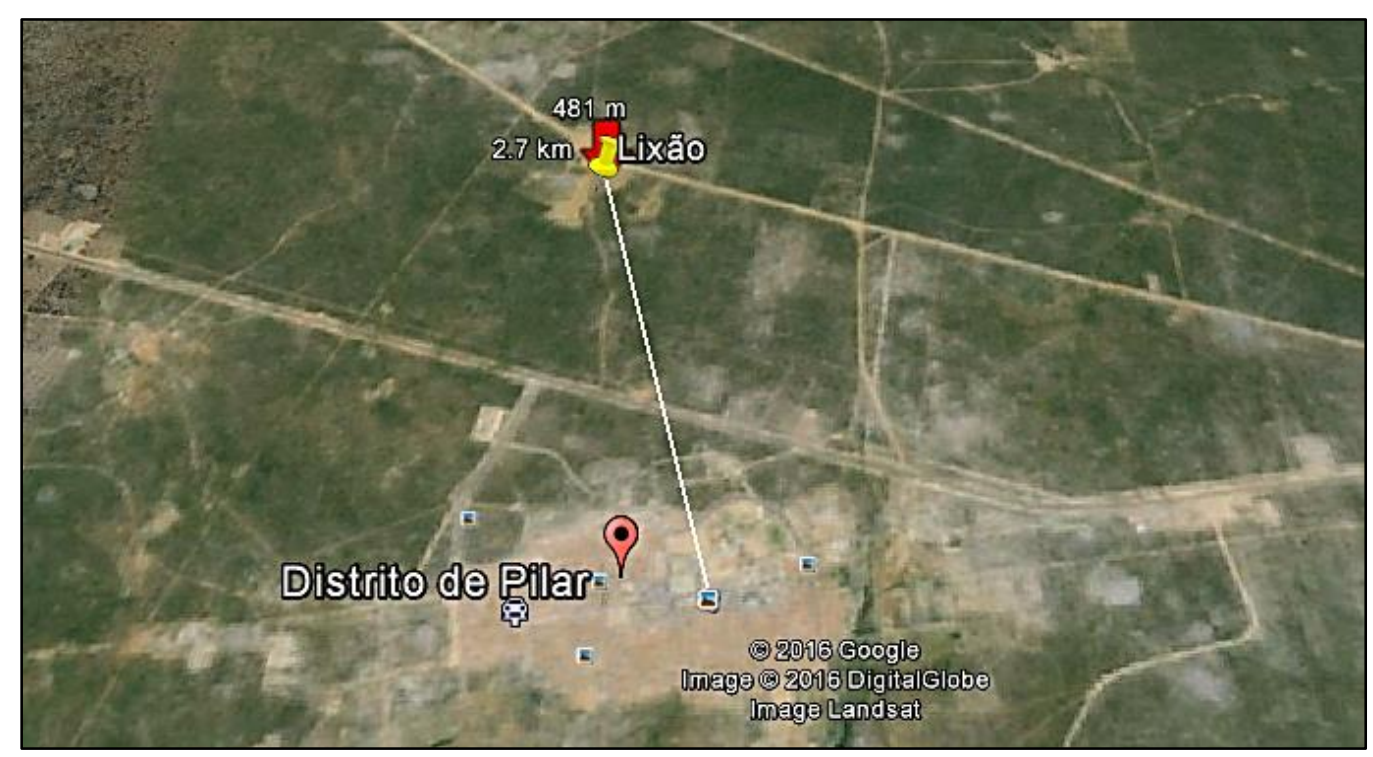

Fonte: Google Earth, 2016. 
Segundo informações da prefeitura a coleta dos resíduos é realizada por uma empresa terceirizada pela prefeitura do Distrito de Pilar, responsável pelo encolhimento dos resíduos encaminhando-os ao lixão. O serviço de limpeza urbana acontece de forma regular, com frequência média de três vezes por semana, por meio de caminhões. Os resíduos são recolhidos nas vias residenciais e comerciais realizados com um (1) caminhão e seis (6) funcionários.

\section{Resultados e Discussão}

\section{Disposição dos resíduos sólidos no Distrito Pilar}

A área em estudo apresenta como principal característica a presença de resíduos sólidos dispostos de maneira irregular. Quanto à origem dos resíduos dispostos no local são que provenientes de ambientes domiciliares, públicos, comercias e/ou industriais.

Análise in loco apresenta aspectos da área de disposição final dos resíduos sólidos urbanos do Distrito do Pilar, como: Resíduos descartado a céu aberto, sem qualquer cuidado na sua disposição, depositados ao longo dos anos.

Ainda referente a Figura 1, observa-se que os resíduos estão depositados em contato direto com o solo. A diversidade de materiais ali presentes apresentam diferentes composições nos quais podem conter metais pesados, hidrocarbonetos, compostos voláteis, dentre outros. Estes componentes são liberados no ambiente a partir da decomposição dos resíduos sólidos e a mistura desses diferentes compostos degradados forma o um líquido escuro (chorume) no qual a depender do tipo de solo presente no local, o mesmo percola no perfil contaminando o lençol freático e consequentemente os recursos hídricos da região. 
Figura 1. Resíduos sólidos urbanos dispostos a céu aberto em processo de degradação no Distrito Pilar, em Jaguarari (BA).

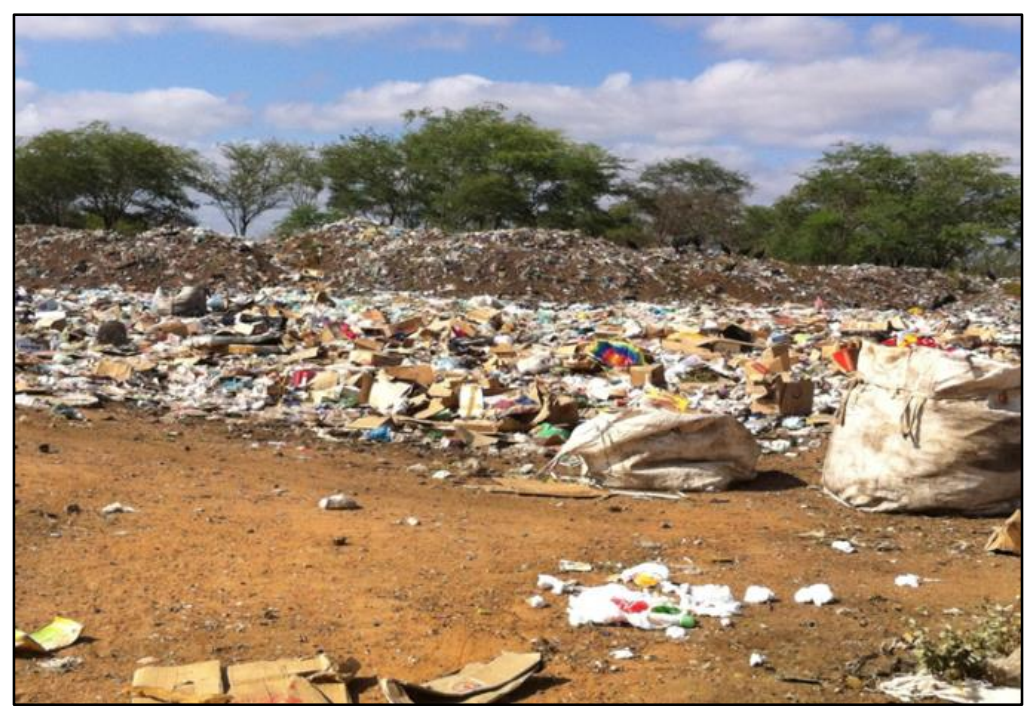

Figura 2. Resíduos sólidos atraindo urubus no Distrito Pilar, em Jaguarari (BA).

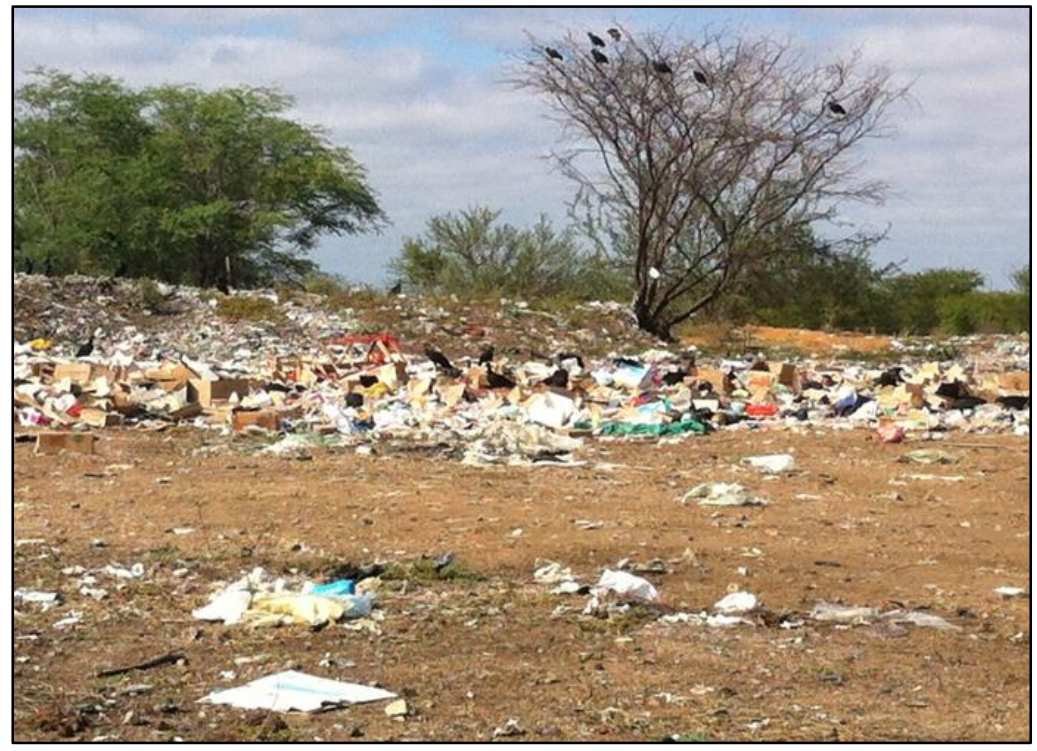

Constatou-se também a presença de animais no local, como a de urubus (Coragyps atratus), cachorros (Figura 2) e insetos. Esses animais encontraram neste local o ambiente altamente propício ao seu desenvolvimento devido à presença em abundância de alimentos que fazem parte das suas cadeias alimentar. Beli et al. (2005, p. 136), em trabalho 
desenvolvido em locais semelhantes também constatou a presença de animais nos lixões em busca de alimentos, que são vetores potenciais de contaminação à população.

O principal problema é que a disposição dos resíduos aproxima esses animais das pessoas que trabalham ou que moram próximo do lixão. Sabe-se que são inúmeras as doenças que são transmitidas por esses animais.

Figura 3. Presença de catadores e suas respectivas moradias no local de descarte de lixo no Distrito Pilar, em Jaguarari/BA.
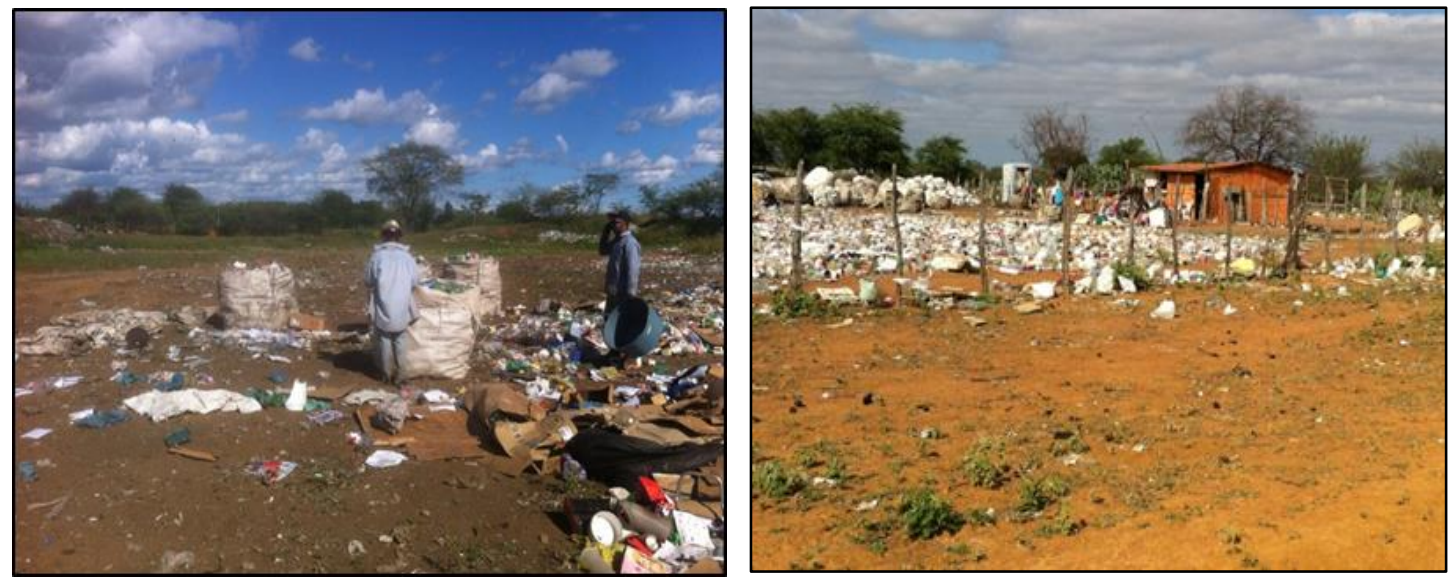

No lixão também foi encontrado catadores que tiram daquele ambiente o seu sustento diário. De acordo a Figura 3, essas pessoas exercem o contato direto com os resíduos e tem suas residências fixadas no local. Há uma preocupação evidente porque os resíduos sólidos do lixão, como já mencionado, favorecem a proliferação de micro e macro vetores. Esses vetores podem ser vias de acesso de agentes patogênicos para os catadores que realizam as atividades de catação sem qualquer tipo de equipamento de proteção individual. Constata-se também que as suas moradias ficam expostas à riscos físicos e biológicos.

Evidências semelhantes foram encontradas por Santos (2012), verificando-se que, os resíduos sólidos urbanos mal acondicionados significam poluição ambiental e risco à saúde da população, sendo fonte de vetores que disseminam doença à população, contaminação dos solos que pode alcançar o lençol freático, contaminando as águas. Em Bragança essa realidade é vivenciada, pois os resíduos sólidos são acondicionados de forma inadequada, e lançados ao ambiente sem nenhum tratamento, ocasionado odor e sérias doenças, principalmente na população que reside nos lixões, sendo resultado direto da falta de conscientização das pessoas e de políticas públicas. 
Os resíduos sólidos do lixão estão expostos a céu aberto conforme na figura 4, portanto, favorecem a proliferação de micro e macrovetores. Esses vetores podem ser vias de acesso de agentes patogênicos para os catadores que realizam as atividades de catação sem qualquer tipo de equipamento de proteção. Suellen em (2008) no seu trabalho realizado Campina grande (PB),descreve as questões do lixão como: Ambientes propícios para a proliferação de macro e micro vetores, como ratos, baratas, mosquitos, bactérias, vírus, dentre outros, que são responsáveis pela transmissão de várias doenças, como leptospirose, dengue, diarréia, febre tifóide, etc.

Em suma, a situação do espaço destinado aos RSU, encontra-se em condições precárias. O lixo que é recolhido na cidade é apenas despejado à céu aberto sem que os cuidados de minimização de impacto ou monitoramento sejam tomados. Desta forma o problema dos resíduos gerados no meio urbano são apenas transferidos para um local afastado, no meio rural, sem a segregação correta.

Existe na cidade a necessidade imediata de um gerenciamento adequado dos resíduos sólidos, para a redução dos impactos ambientais, garantindo uma melhoria na qualidade ambiental. Pretende-se com essas análises mostrar aos geradores que com medidas simples que já podem está sendo desenvolvidas, mas que precisam de ajustes é possível melhorar o gerenciamento dos resíduos sólidos no Distrito.

\section{Diagnóstico Ambiental geral do lixão do Distrito do Pilar.}

De acordo com a entrevista aos moradores próximos do lixão, verificou-se que os componentes ambientais de ordem física, química, biológica vem sendo alterados, ou seja, os impactos ambientais são evidentes e boa parte desses são tidos dentro da modalidade direta. O primeiro deles a ser relatado é o mau cheiro, O que ocasionou não somente o desequilíbrio ambiental, mas também a proliferação de insetos.

Outra adversidade visual são os resíduos lançado, presença de animais, os quais elimina seus dejetos no local, os quais proporcionam o surgimento de doenças, tais como: esquistossomose. 
Conforme o questionário aplicado com alguns funcionários da prefeitura da localidade citada, obteve algumas informações em relação à aplicação do projeto de um Aterro Sanitário juntamente com a Cidade Jaguarari, o qual foi iniciado, porém foi interrompido devido à falta de recursos para a finalização do mesmo. É necessário que se aplique um trabalho educacional para toda a população sensibilizando na importância de cuidar do meio ambiente, reduzindo a quantidade de resíduos despejado de forma incorreta. Logo, terá grandes resultados na redução de resíduos melhorando o Distrito Pilar.

\section{Conclusão}

De acordo com os resultados obtidos foi detectado a presença de resíduos sólidos dispostos de maneira irregular, proporcionando impactos ambientais, a presença de animais que pode ser fonte de contaminação às pessoas que ali residem.

Contudo, o entendimento sobre a geração dos resíduos sólidos, as noções de repensar suas reais necessidades de consumo, e ainda praticar a separação dos resíduos, visando minimizar a produção de resíduos são atributos a serem alcançados pelos moradores.

\section{Referências Bibliográficas}

ABES INFORMA -Informativo Eletrônico da Associação Brasileira de Engenharia Sanitária e Ambiental. Lixão é Problema em Cidades Pequenas, no. 287, 25 de Julho de 2012.

ALCÂNTARA, A. J. O. Composição gravimétrica dos resíduos sólidos urbanos e caracterização química do solo da área de disposição final do município de Cáceres-MT. Cáceres, 2010. Dissertação (Programa de pós-graduação em Ciências Ambientais), Universidade do Estado do Mato Grosso.

ARAÚJO, B. G. P.; OLIVEIRA JÚNIOR, E. F.; VIEIRA JUNIOR, A. S. Resíduos Sólidos Urbanos: análise sobre a situação do conjunto Albano Franco - Riachão do Dantas-SE. 2013. 
ASSOCIAÇÃO BRASILEIRA DE EMPRESAS DE LIMPEZA PÚBLICA E RESÍDUOS ESPECIAIS (ABRELPE). Panorama dos resíduos sólidos no Brasil 2011

ASSOCIAÇÃO BRASILEIRA DE NORMAS TÉCNICAS. NBR 10.004: Resíduos sólidosclassificação. Rio de Janeiro, 2004.

BELI, E.; NALDONI, C. E.; OLIVEIRA,A.; SALES, M. R.; SIQUEIRA, M.; MEDEIROS, G. A.; HUSSAR,G. J.; REIS, F. A. G. V. Recuperação da área degradada pelo lixão areia branca de Espírito Santo do Pinhal-SP.

IBGE, Instituto Brasileiro de Geografia e Estatística, 2000.

JUNKES, M. B. et al. Procedimentos para aproveitamento de residuos sólidos urbanos em municípios de pequeno porte. Programa de Pós-Graduação em Engenharia de Produção. Dissertação (mestrado) - Universidade Federal de Santa Catarina, 2002.

LEITE, V. D.\& LOPES, W. S. Avaliação dos aspectos sociais, econômicos e ambientais causados pelo lixão da cidade de Campina Grande - PB. In: IX Simpósio Luso Brasileiro de Engenharia Sanitária e Ambiental. Porto Seguro - Brasil, 2000, p. 15341540.

PEREIRA, S.S; MELO, J.A.B. Gestão dos resíduos sólidos urbanos em Campina Grande/PB e seus reflexos socioeconômicos. Revista Brasileira de Gestão e Desenvolvimento Regional. v.4, n.4, p. 193-217, Taubaté, SP, 2008.

SANTOS, L. F. P dos. Indicadores de Salubridade Ambiental (ISA) e sua aplicação para a gestão urbana. 2012. 131 f. Dissertação (Mestrado em Direito Ambiental e Políticas Públicas), Universidade Federal do Amapá, Macapá.

Silva, J.A.; Souza, V. \& Moura, J.M. Gestão de resíduos sólidos domiciliares em Cuiabá: Gerenciamento integrado. II Congresso Brasileiro de Gestão Ambiental, 2011, Londrina-PR.

SIQUEIRA, M.M.; MORAES, M.S. Saúde coletiva, resíduos sólidos urbanos e os catadores de lixo. Ciência \& Saúde Coletiva, v.14, n.6, Rio de Janeiro, 2009. 
SUELLEN, MELO. Gestão dos resíduos sólidos urbanos em Campina Grande/PB e seus reflexos socioeconômicos, G\&DR v. 4, n. 4, p. 193-217, set-dez/2008

\section{ANEXO 1.}

QUESTIONÁRIO APLICADO COM ALGUNS FUNCIONÁRIOS DA PREFEITURA

$\underline{\text { Dados do entrevistado: }}$

Nome:

Cargo:

1. O município tem projeto para área de disposição final?

2. Existe algum projeto de implantação de Aterro sanitário ou Gerenciamento dos resíduos sólidos urbanas?

3. O que a sociedade já fez para melhorar ou recuperar as características do Lixão?

4. Existe algum trabalho educacional com a sociedade para controlar ou até mesmo acabar com a atividade de lançamento de resíduos disposta de maneira irregular?

ANEXO 2.

QUESTIONÁRIO COM MORADORES QUE MORA NAS PROXIMIDADES DO LIXÃO

Dados do entrevistado:

Nome:

Profissão: 
1. Você mora há quanto tempo nas proximidades do Lixão?

2. Quais as alterações você percebe em relação ao meio ambiente?

3. Mosquitos, insetos maus odores incomodam?

4. Quais alterações você observou no ecossistema do local? 